(6) OPEN ACCESS

\title{
Management of patients on antithrombotic agents undergoing emergency and elective endoscopy: joint Asian Pacific Association of Gastroenterology (APAGE) and Asian Pacific Society for Digestive Endoscopy (APSDE) practice guidelines
}

\author{
Francis K L Chan, ${ }^{1}$ Khean-Lee Goh, ${ }^{2}$ Nageshwar Reddy, ${ }^{3}$ Kazuma Fujimoto, ${ }^{4}$ \\ Khek Yu Ho, ${ }^{5}$ Seiji Hokimoto, ${ }^{6}$ Young-Hoon Jeong, ${ }^{7}$ Takanari Kitazono, ${ }^{8}$ Hong Sik Lee, ${ }^{9}$ \\ Varocha Mahachai, ${ }^{10}$ Kelvin K F Tsoi, ${ }^{11}$ Ming-Shiang Wu, ${ }^{12}$ Bryan P Yan, ${ }^{13}$ \\ Kentaro Sugano ${ }^{14}$
}

For numbered affiliations see end of article.

\section{Correspondence to} Professor Francis K L Chan, Department of Medicine and Therapeutics, The Chinese University of Hong Kong, Hong Kong, China; fklchan@cuhk. edu.hk

Received 23 August 2017 Revised 6 December 2017 Accepted 9 December 2017 Published Online First 13 January 2018
Check for updates

To cite: Chan FKL, Goh K-L, Reddy N, et al. Gut

2018:67:405-417

\section{ABSTRACT}

This Guideline is a joint official statement of the Asian Pacific Association of Gastroenterology (APAGE) and the Asian Pacific Society for Digestive Endoscopy (APSDE). It was developed in response to the increasing use of antithrombotic agents (antiplatelet agents and anticoagulants) in patients undergoing gastrointestinal (GI) endoscopy in Asia. After reviewing current practice guidelines in Europe and the USA, the joint committee identified unmet needs, noticed inconsistencies, raised doubts about certain recommendations and recognised significant discrepancies in clinical practice between different regions. We developed this joint official statement based on a systematic review of the literature, critical appraisal of existing guidelines and expert consensus using a two-stage modified Delphi process. This joint APAGE-APSDE Practice Guideline is intended to be an educational tool that assists clinicians in improving care for patients on antithrombotics who require emergency or elective $\mathrm{Gl}$ endoscopy in the Asian Pacific region.

\section{BACKGROUND}

Antithrombotic agents, which include antiplatelet agents and anticoagulants, are increasingly used in Asia. Management of patients on antithrombotics undergoing emergency or elective gastrointestinal (GI) endoscopy has become a common and important clinical challenge. While practice guidelines have been developed by GI and endoscopy societies in the USA, ${ }^{1}$ Europe $^{2}$ and the UK, ${ }^{3}$ it was uncertain whether they should be fully adopted in the Asian Pacific region. In September 2015 the Asian Pacific Association of Gastroenterology (APAGE) and the Asian Pacific Society for Digestive Endoscopy (APSDE) appointed KS and FKLC to form an ad hoc working group to evaluate current practice guidelines on the management of patients on antithrombotics undergoing GI endoscopy. In collaboration with the Institute of Digestive Disease of The Chinese University of Hong Kong (CUHK), we systematically reviewed the evidence supporting published guidelines. We concluded that the available practice guidelines in Western countries could not completely meet the specific needs of the Asian Pacific region. For example, many Asian countries have a high case load of non-variceal upper GI bleeding. Current guidelines do not provide comprehensive guidance on the management of GI bleeding in patients with high thromboembolic risks. Another example is that invasive endoscopic procedures such as endoscopic submucosal dissection (ESD) are more commonly performed in Asia than in Western countries due to the high prevalence of certain GI cancers. Furthermore, we noticed inconsistencies between different guidelines and raised doubts about certain recommendations (box 1).

In June 2016 a steering committee representing the APAGE and the APSDE (FKLC and KS) and a member nominated by the Japanese Circulation Society (SH) was established to develop practice guideline statements. The steering committee invited members to form a Joint Task Force to participate in the process of finalising guideline development for the Asian Pacific region. Task Force members included gastroenterologists, endoscopists, cardiologists, neurologists and public health specialists. This joint APAGE-APSDE Practice Guideline is intended to be an educational tool that assists clinicians in improving care for patients on antithrombotics who require emergency or elective GI endoscopy in the Asian Pacific region. The Task Force is aware of the fact that clinical decisions for individual patients may lead to deviations of practice from these guidelines. Therefore, this set of guidelines should not be construed as establishing a legal standard of care or as encouraging, advocating, requiring or discouraging any particular treatment.

\section{METHOD}

We performed a systematic literature search to review the management of oral antithrombotic agents in patients undergoing GI endoscopy. Searches of the OVID MEDLINE database were performed using keywords related to antithrombotic 


\section{Box 1 Major differences between Joint APAGE-APSDE Practice Guidelines and other guidelines}

\section{Non-variceal upper GI bleeding}

Platelet transfusion for life-threatening bleeding

- APAGE-APSDE: not recommended

- ASGE: an option for patients on antiplatelet agents

- BSG-ESGE: an option for patients on DOACs

Patient on DAPT

- APAGE-APSDE: continue aspirin, withhold second antiplatelet agent for up to 5 days after endoscopic haemostasis

- ASGE: discuss with cardiologist

- ESGE: continue aspirin, consult cardiologist for resumption of second antiplatelet agent

Patients on warfarin

- APAGE-APSDE: low-dose vitamin K (1-2.5 mg) for warfarin reversal

- ESGE and ACCP: 5-10 mg of vitamin $\mathrm{K}$ for warfarin reversal

Resumption of warfarin

- APAGE-APSDE: resume warfarin by day 3 once adequate haemostasis is achieved; consider bridging with unfractionated heparin if high thrombotic risk (box 2)

ESGE: resume warfarin between 7 and 15 days following the bleeding event for most patients; no mention about bridging

Resumption of DOACS

- APAGE-APSDE: resume DOACs by day 3 once adequate haemostasis is achieved; no heparin bridging

- ASGE/ESGE/BSG-ESGE: not specified

Elective endoscopic procedures

Procedures with high bleeding risks

- APAGE-APSDE: special attention to ultra-high risk procedures

- ASGE: ultra-high procedures not covered

- BSG-ESGE: recognise certain procedures carry very high bleeding risk

Timing of elective procedures in patients with coronary stents or ACS

- APAGE-APSDE: defer procedures within first 6 weeks, high risk from 6 weeks to 6 months, risk is independent of type of coronary stents

- ASGE: defer procedures possibly up to 12 months in patients with DES on DAPT

- BSG-ESGE: risky to discontinue second antiplatelet agent in patients with DES within 12 months or BMS within 1 month of placement

Bridge therapy

- APAGE-APSDE: non-valvular atrial fibrillation with $\mathrm{CHA}_{2} \mathrm{DS}_{2}$-VASC score $>5$

- ASGE: non-valvular atrial fibrillation with $\mathrm{CHA}_{2} \mathrm{DS}_{2}$-VASC score $>2$

BSG-ESGE: non-valvular atrial fibrillation not indicated regardless of $\mathrm{CHA}_{2} \mathrm{DS}_{2}$-VASc score

DOACS

- APAGE-APSDE: no need to omit DOACs before low-risk procedures; resume DOACs when adequate haemostasis is achieved after high-risk procedures; no heparin bridging

- ASGE: no need to omit DOACs before low-risk procedures; resume DOACs until adequate haemostasis is ensured after high-risk procedures; consider heparin bridging if DOACs cannot be resumed within 12-24 hours

- BSG-ESGE: omit morning dose of DOACs on the day of low-risk procedures; delay the resumption of DOACs for at least 24-48 hours after high-risk procedures; no heparin bridging

ACCP, American College of Chest Physicians; ACS, acute coronary syndrome; ASGE, American Society of Gastrointestinal Endoscopy; BMS, bare metal stent; BSG, British Society of Gastroenterology; DAPT, dual antiplatelet therapy; DES, drug eluting stent; DOACs, direct oral anticoagulants; ESGE, European Society of Gastrointestinal Endoscopy.

agents, gastrointestinal and endoscopy. The search duration was from 1 January 1990 to 31 July 2016. Publications were identified by title; their relevance was then determined by reviewing the abstract of all records. Studies were excluded if the content was considered irrelevant. The initial guideline statements were drafted based on published systematic reviews, meta-analyses, randomised controlled trials and prospective and retrospective observational studies. A collection of selected literature was made available to all panel members.

A two-stage modified Delphi process was used to develop consensus. The first vote was conducted anonymously with an internet-based voting platform. Each member was asked to rank each statement on a 6-point Likert scale, where $\mathrm{A}+$ indicated agree strongly and D+ indicated disagree strongly. Feedback was solicited on the statements and the results were collated (vote 1). Agreement with a statement (A+ or A) by at least $80 \%$ of the Task Fforce was defined a priori as consensus. A faceto-face meeting of the Task Force was held on 2-3 September 2016 in Tokyo, Japan. During the meeting the results of vote 1 were shown, and suggested modifications to the statements were discussed. Members discussed statements with divergent opinions. A second vote was cast on all statements by using electronic keypads to ensure anonymity (vote 2). Focused discussion was carried out on those statements that failed to reach consensus, followed by a third vote, again by using electronic keypads (final vote). The consensus method did not force agreement. The level 
Table 1 Stratification of elective endoscopic procedures based on the risk of haemorrhage

\begin{tabular}{lll}
\hline Low risk* & High risk & Ultra-high riskt \\
\hline Diagnostic endoscopy with biopsy & Polypectomy & Endoscopic submucosal dissection \\
\hline Endoscopic ultrasound without fine needle aspiration & ERCP with sphincterotomy \pm balloon sphincteroplasty & Endoscopic mucosal resection of large (>2 cm) polyps \\
\hline ERCP with biliary or pancreatic stenting & Dilatation of strictures & \\
Diagnostic push or device-assisted enteroscopy & Injection or banding of varices \\
\hline Video capsule endoscopy & Percutaneous endoscopic gastrostomy or jejunostomy & \\
Oesophageal, enteral and colonic stenting & Endoscopic ultrasound with fine needle aspiration & \\
\hline Argon plasma coagulation & Ampullectomy & \\
\hline
\end{tabular}

*We recommend continuation of antiplatelet agents and/or anticoagulants.

tWe recommend discontinuation of all antiplatelet agents and/or anticoagulants.

ERCP, endoscopic retrograde cholangiopancreatography.

of agreement in the final vote was given for each statement, which was expressed as the percentage vote at each point on the Likert scale. The recommendations were graded using the Grading of Recommendations Assessment, Development and Evaluation (GRADE) system. ${ }^{4}$ The APAGE and APSDE endorsed the consensus meeting.

\section{Funding source}

The funding of this Joint Task Force was derived from an educational grant from the Institute of Digestive Disease of CUHK and sponsorship from Takeda Pharmaceuticals Company Limited. The sponsor was not involved in panel member selection, development of practice guidelines or manuscript preparation. Panel members received no honoraria.

Our guidelines are categorised according to the urgency of the endoscopy (ie, emergency and elective). We arbitrarily define bleeding that causes a high likelihood of death as life-threatening. Under each category, the recommendations are divided into the type of antithrombotics used (ie, single antiplatelet agent, dual antiplatelet therapy and anticoagulants). Anticoagulants are subdivided into warfarin and direct anticoagulants (DOACs). For elective procedures, we classified them as low-risk, high-risk and ultra-high risk (table 1). We attempted to provide recommendations on the management of antithrombotic therapy according to the thrombotic risk of patients (table 2 and box 2).

\section{SUMMARY OF RECOMMENDATIONS: EMERGENCY ENDOSCOPY FOR NON-VARICEAL UPPER GI BLEEDING}

The Joint Task Force has established the following guideline statements and recommendations according to the type of antithrombotic therapy received by patients.

\section{Single antiplatelet agent}

1. We recommend withholding aspirin before endoscopy in aspirin users presenting with serious or life-threatening

Table 2 Management of antithrombotic therapy in elective endoscopic procedures with high bleeding risks

\begin{tabular}{|c|c|c|}
\hline Thrombotic risk category & Cardiac events* & Antithrombotic therapy in high bleeding risk elective procedures \\
\hline Very high & $\mathrm{ACS}$ or $\mathrm{PCl}<6$ weeks & - Defer procedure \\
\hline High & ACS or $\mathrm{PCl} 6$ weeks -6 months ago & $\begin{array}{l}\text { Defer procedure until }>6 \text { months after cardiac event if possible } \\
\text { If elective procedure is deemed necessary within } 6 \text { months: } \\
\text { DAPT } \\
\text { Continue aspirin } \\
\text { Withhold P2Y12 receptor inhibitors } 5 \text { days before } \\
\text { Wesume P2Y12 receptor inhibitors after adequate haemostasis } \\
\text { Withhold warfarin } 5 \text { days before } \\
\text { Resume warfarin after adequate haemostasis } \\
\text { Heparin bridging } \\
\text { DOACs } \\
\text { Withhold DOACs } 2 \text { days before } \\
\text { Resume DOACs after adequate haemostasis } \\
\text { No heparin bridging }\end{array}$ \\
\hline Moderate to low & $\begin{array}{l}\text { ACS or } \mathrm{PCI}>6 \text { months ago; } \\
\text { stable coronary artery disease }\end{array}$ & $\begin{array}{l}\text { Antiplatelet agents } \\
\text { Continue aspirin } \\
\text { Withhold P2Y12 receptor inhibitors } 5 \text { days before } \\
\text { Wesume P2Y12 receptor inhibitors after adequate haemostasis } \\
\text { Withhold warfarin } 5 \text { days before } \\
\text { Resume warfarin after adequate haemostasis } \\
\text { No heparin bridging } \\
\text { DOACs } \\
\text { Withhold DOACs } 2 \text { days before } \\
\text { Resume DOACs after adequate haemostasis } \\
\text { No heparin bridging }\end{array}$ \\
\hline
\end{tabular}

\footnotetext{
${ }^{*}$ Current evidence indicates that new generation drug-eluting stents and bare metal stents carry similar thrombotic risks. The risk is highest within the first 6 weeks of PCl. The risk
} remains high from 6 weeks to 6 months, then remains constant thereafter. ${ }^{88} 89$

ACS, acute coronary syndrome; DAPT, dual antiplatelet therapy; DOACs, direct oral anticoagulants; PCl, percutaneous coronary intervention. 
Box 2 Indications of heparin bridging for temporary discontinuation of warfarin

- Non-valvular atrial fibrillation with a $\mathrm{CHA}_{2} \mathrm{DS}_{2}$-VASC score $>5^{*}$

- Metallic mitral valve

- Prosthetic valve with atrial fibrillation

- <3 months after VTE

- Severe thrombophilia (protein C or protein S deficiency, antiphospholipid syndrome)

${ }^{*} \mathrm{CHA}_{2} \mathrm{DS}_{2}$-VASC, congestive heart failure (1 point), hypertension (1 point), age $\geq 75$ years ( 2 points), diabetes mellitus (1 point), stroke, TIA or thromboembolism (2 points), vascular disease (1 point), age 65-74 years (1 point), female sex (1 point). ${ }^{92} 93$

VTE, venous thromboembolism.

GI bleeding in places where emergency endoscopy is not readily available. (A+58\%, A 42\%; strong recommendation; low-quality evidence)

2. We do not recommend platelet transfusion because it does not improve the clinical outcome of patients on antiplatelet agents. (A+ 60\%, A 33\%, D- 7\%; strong recommendation; low-quality evidence)

3. We recommend early resumption of aspirin, preferably within 3-5 days after endoscopic haemostasis. (A+ 80\%, A $13 \%$, D 7\%; strong recommendation; moderate-quality evidence)

\section{Dual antiplatelet therapy (DAPT)}

4. For patients with coronary stents on DAPT, the Task Force does not recommend withholding both antiplatelet agents due to high risk of stent thrombosis. (A+ 67\%, A 27\%, A$6 \%$; strong recommendation; low-quality evidence)

5. For patients on proton-pump inhibitor infusion and DAPT with aspirin and clopidogrel, the Task Force recommends continuing aspirin and withholding clopidogrel. (A+ 64\%, A $27 \%$, A- $9 \%$; strong recommendation; low-quality evidence)

6. In patients with drug-eluting coronary stents we recommend early resumption of P2Y12 receptor inhibitor, preferably within 5 days after endoscopic haemostasis. (A+ 67\%, A 33\%; strong recommendation; low-quality evidence)

\section{Warfarin}

7. We recommend withholding warfarin to facilitate haemostasis. (A+ 71\%, A 29\%; strong recommendation; low-quality evidence)

8. We recommend 4-factor prothrombin complex concentrate (PCC) plus low-dose vitamin $\mathrm{K}$ for life-threatening bleeding with an INR above 2.5. (A+ 50\%, A 50\%; strong recommendation; low-quality evidence)

9. We do not recommend delaying endoscopy for life-threatening bleeding until normalisation of INR. (A+ 64\%, A $21 \%$, A - 7\%, D 7\%; strong recommendation; low-quality evidence)

10. Rechecking INR after reversal therapy is not mandatory before endoscopy. (A+ 40\%, A 50\%, A- 10\%; weak recommendation; low-quality evidence)

11. We do not recommend higher doses of vitamin $\mathrm{K}(>5 \mathrm{mg})$ in patients with high thromboembolic risk. (A+ 60\%, A $40 \%$; strong recommendation; moderate-quality evidence)
12. In patients with high thromboembolic risk, resume warfarin once adequate haemostasis is achieved. (A +59\%, A 33\%, A- 8\%; strong recommendation; low-quality evidence)

13. We do not recommend bridging anticoagulation therapy in patients with low thromboembolic risk. (A+ 50\%, A 50\%; strong recommendation; moderate-quality evidence)

14. We recommend bridging anticoagulation with unfractionated heparin in patients with high thromboembolic risk. (A+ 50\%, A 50\%; strong recommendation; low-quality evidence)

\section{Direct oral anticoagulants (DOACs)}

15. We recommend withholding DOACs to facilitate haemostasis. (A+ 50\%, A 43\%, D 7\%; strong recommendation; low-quality evidence)

16. We recommend activated charcoal for life-threatening bleeding if the last dose of DOAC is taken within 3 hours. (A+ 25\%, A 67\%, D 8\%; strong recommendation; low-quality evidence)

17. We recommend idarucizumab for the treatment of life-threatening bleeding in patients on dabigatran. (A+ 50\%, A 50\%; strong recommendation; low-quality evidence)

18. We do not recommend vitamin $\mathrm{K}$ for treatment of bleeding associated with DOACs. (A+ 79\%, A 14\%, D 7\%; strong recommendation; low-quality evidence)

19. We recommend resuming DOACs after adequate haemostasis is achieved. (A+75\%, A 25\%; strong recommendation; low-quality evidence)

20. We do not recommend bridging therapy in patients on DOACs. (A+ 57\%, A 36\%, D 7\%; strong recommendation; low-quality evidence)

\section{Single antiplatelet agent}

In the Asian Pacific region, aspirin is most commonly used for established cardiovascular diseases whereas primary prophylaxis with aspirin is still uncommon. Primary prevention trials conducted in Japan failed to show any benefits of aspirin for cardiovascular events. ${ }^{5}$ Other new non-aspirin antiplatelet agents, including P2Y12 receptor inhibitors (prasugrel and ticagrelor) and protease-activated receptor (PAR-1) antagonist (vorapaxar), are mostly used together with aspirin and will be discussed below under 'Dual antiplatelet therapy (DAPT)'.

Most major hospitals in Asia are able to provide an after office hours emergency endoscopy service for patients with life-threatening bleeding. Patients with unstable haemodynamics often undergo endoscopy within 12 hours. However, the Task Force considers that withholding aspirin before endoscopy is relevant in places where emergency endoscopy is not readily available. That being said, emergency endoscopy should not be delayed in aspirin users because the antiplatelet effect of aspirin will last for 5-7 days after the last dose taken. Currently available guidelines do not give a consistent recommendation. The American Society of Gastrointestinal Endoscopy (ASGE) Practice Guidelines recommend all patients on antiplatelet agents with life-threatening or serious GI bleeding should have these agents held only after discussion with their cardiologist. ${ }^{1}$ In contrast, the European Society of Gastrointestinal Endoscopy (ESGE) Guidelines recommend withholding aspirin until day 3 after endoscopic treatment of high-risk stigmata. ${ }^{2}$

While ASGE Practice Guidelines mention platelet transfusion as an option for patients on antiplatelet agents with life-threatening or serious bleeding, ${ }^{1}$ we do not recommend platelet transfusion as a treatment option because there is no good evidence 
to support this practice. In a retrospective cohort study of 204 patients receiving antiplatelet agents with GI bleeding, platelet transfusion did not reduce rebleeding but was associated with higher mortality. ${ }^{7}$ Although the increase in mortality could be due in part to residual bias associated with more severe bleeding in cases than controls, the lack of benefit of platelet transfusion does not support its use in patients with GI bleeding who are receiving antiplatelet agents.

The timing of resuming aspirin after non-variceal upper GI bleeding is critical in terms of the risks of early rebleeding and serious cardiovascular outcomes. In a double-blind randomised trial conducted in Hong Kong, 156 aspirin users with established cardiovascular diseases who had actively bleeding peptic ulcers were randomised to resume aspirin or placebo immediately after endoscopic haemostasis. ${ }^{8}$ At 8 weeks, all-cause mortality was 10 times lower in the aspirin group than in the placebo group (1.3\% vs $12.9 \%$; $95 \%$ CI $3.7 \%$ to $19.5 \%)$, although the 30 -day rebleeding rate was numerically two times higher in the aspirin group. In another retrospective study of 118 aspirin users who had peptic ulcer bleeding, $40 \%$ of patients discontinued aspirin. In a median follow-up of 2 years, patients with cardiovascular comorbidities who discontinued low-dose aspirin therapy had an almost sevenfold increase in risk for death or acute cardiovascular events (HR 6.9; 95\% CI 1.4 to 34.8) compared with patients who continued this therapy during the first 6 months of the follow-up period. ${ }^{9}$

\section{Dual antiplatelet therapy (DAPT)}

The Task Force recommends discussion with the cardiologist before discontinuation of antiplatelet therapy, particularly in patients with acute coronary syndrome within 6 months, because these patients have a higher risk of stent thrombosis than patients with stable coronary artery disease. ${ }^{10}$ As a general principle, we do not recommend withholding both antiplatelet agents simultaneously because the median time to coronary stent thrombosis can be as short as 7 days with both drugs withheld compared with 122 days with only clopidogrel withheld. ${ }^{11}$ Whether one should temporarily discontinue aspirin or clopidogrel in acute non-variceal upper GI bleeding remains controversial. The ESGE Guidelines recommend continuation of aspirin without interruption and consultation with a cardiologist for resumption of second antiplatelet agent after GI bleeding. ${ }^{2}$ However, no justification was provided for this recommendation.

In patients on DAPT with aspirin and clopidogrel, we recommend continuing aspirin and withholding clopidogrel in acute non-variceal upper GI bleeding for two reasons. First, there is evidence that continuation of aspirin alone delays the onset of coronary events in patients on DAPT. ${ }^{11}$ Second, high-dose proton-pump inhibitors (PPIs) will be used in the management of acute bleeding. The prevalence of slow metabolisers of CY2C19 is as high as $25 \%$ in certain Asian populations compared with less than 5\% in Western populations. ${ }^{12}{ }^{13}$ Whether there is any clinically important interaction between PPIs and clopidogrel remains controversial. ${ }^{14}$ The Food and Drug Administration has issued a warning label against the concomitant use of clopidogrel and PPIs that are extensively metabolised by CYP2C19. ${ }^{15}$ In a subgroup analysis of a French registry of acute myocardial infarction there was a threefold increased risk of serious cardiovascular outcomes $(12 \%)$ in the cohort of PPI users with two loss-of-function alleles compared with the cohort with wild type CY2C19 (4\%). ${ }^{16}$ Our Task Force cannot exclude the possibility that use of high-dose PPI in slow metabolisers of CYP2C19 may reduce the efficacy of clopidogrel. We therefore recommend discontinuing clopidogrel while continuing aspirin in Asian patients receiving DAPT for coronary stents complicated by acute non-variceal upper GI bleeding.

Other new P2Y12 receptor inhibitors include prasugrel and ticagrelor. They are more potent and reported to have a higher risk of major spontaneous bleeding compared with clopidogrel. ${ }^{17}{ }^{18}$ Similar to clopidogrel, prasugrel irreversibly inhibits platelet function. In contrast, ticagrelor is a reversible P2Y12 receptor inhibitor with platelet function returning in 3-5 days after discontinuation (compared with about 5 days for clopidogrel and 7 days for prasugrel). It follows that, in acute non-variceal upper GI bleeding, patients with drug-eluting coronary stents should resume ticagrelor preferably within 2-3 days whereas re-initiation of clopidogrel and prasugrel can be delayed up to 5 days after endoscopic haemostasis. However, there are no clinical data on the optimal timing of re-initiation of P2Y12 receptor inhibitors in GI bleeding.

Another new antiplatelet agent is vorapaxar, a protease-activated receptor (PAR-1) antagonist that inhibits thrombin receptor. It is indicated in patients with a history of myocardial infarction or peripheral arterial disease, and is usually prescribed in addition to DAPT. ${ }^{19}$ Due to its increased risk of intracranial haemorrhage, vorapaxar is contraindicated in patients with a history of stroke, transient ischaemic attack or intracranial haemorrhage. Currently, vorapaxar is not yet approved in some Asian countries including Japan. To date, there are no data on the GI procedural risk associated with vorapaxar.

\section{Warfarin}

Current guidelines recommend reversal of anticoagulation in patients with serious life-threatening bleeding irrespective of whether the INR is at therapeutic or supra-therapeutic levels. $^{20}{ }^{21}$ However, available evidence does not show any correlation between INR at presentation and outcomes of GI bleeding. A number of retrospective studies reported a very high initial success rate of endoscopic haemostasis (>95\%) in anticoagulated patients with baseline INR between 1.5 and $2.5^{22} 23$ A systematic review of over 1800 patients found that INR at presentation did not predict recurrent non-variceal upper GI bleeding. ${ }^{24}$ We therefore do not recommend normalising INR in all patients as it may delay endoscopy for life-threatening bleeding. Although no randomised clinical trials have been performed to compare prothrombin complex concentrate (PCC) with fresh frozen plasma (FFP) for warfarin reversal in acute GI bleeding, we recommend a combination of 4-factor PCC and low-dose vitamin $\mathrm{K}(<5 \mathrm{mg})$ if urgent reversal of anticoagulation is deemed necessary. PCC, which contains clotting factors from pooled human plasma, has a number of advantages over fresh frozen plasma, including no need for $\mathrm{ABO}$ matching, faster onset of action and minimal risk of fluid overload and transmitting infection. ${ }^{25-27}$ Factor VII, which is present in 4-factor PCC and fresh frozen plasma, has a short half-life of about 4 hours. We recommend concomitant replacement with vitamin $\mathrm{K}$, either orally or intravenously, to restore endogenous factor VII. Both ESGE $^{2}$ and American College of Chest Physicians' (ACCP) practice guidelines recommend $5-10 \mathrm{mg}$ vitamin $\mathrm{K}$ for life-threatening bleeding. ${ }^{28}$ In contrast, we recommend low-dose vitamin $\mathrm{K}(<5 \mathrm{mg})$ especially in patients for whom early re-anticoagulation is necessary to reduce the risk of hypercoagulopathy. Our recommendation is based on evidence from four randomised trials that the optimal doses of vitamin $\mathrm{K}$ for normalisation of INR are between 1 and $2.5 \mathrm{mg} .^{29-32}$ 
There is evidence from retrospective data that early resumption of warfarin is associated with a lower risk of thromboembolism and death. ${ }^{33}$ The optimal timing of resuming warfarin depends on the thrombotic risk of individual patients (box 2). A number of retrospective studies have shown that resumption of warfarin between 7 and 30 days significantly reduced the risk of thromboembolism and death without increasing the risk of rebleeding, whereas resuming warfarin within 7 days of the bleeding episode was associated with a twofold increased risk of rebleeding. ${ }^{3435}$ However, a note of caution is that the available data were derived from a heterogeneous group of patients with different thrombotic risks.

Since the risk of early rebleeding decreases considerably after the first 3 days and the time required for full re-anticoagulation may be prolonged, especially after warfarin reversal, we recommend early resumption of warfarin after day 3, especially in patients with high thromboembolic risk. According to the ESGE guidelines, ${ }^{2}$ the timing for resumption of anticoagulation should be assessed on a patient-by-patient basis. They recommend that resuming warfarin between 7 and 15 days following the bleeding event appears safe and effective in preventing thromboembolic complications for most patients. ${ }^{2}$

The joint British Society of Gastroenterology (BSG) and European Society of Gastrointestinal Endoscopy (ESGE) Guidelines (abbreviated as BSG-ESGE guidelines) recommend bridging therapy using low molecular weight heparin (LMWH) for patients at high thrombotic risk undergoing elective endoscopy. ${ }^{3}$ While we agree with the above guideline for uncomplicated elective procedures, we recommend using unfractionated heparin as bridging therapy after emergency endoscopy for bleeding in patients with high thrombotic risk. This is because unfractionated heparin has a much shorter half-life (1-2 hours after intravenous injection) that allows rapid reversal in case rebleeding occurs. $^{36}$

\section{Direct oral anticoagulants (DOACs)}

To date, four DOACs including dabigatran, apixaban, rivaroxaban and edoxaban have been approved by the FDA and are available in many countries in the Asia Pacific region. Unlike vitamin $\mathrm{K}$ antagonists, DOACs are direct inhibitors of factor thrombin (dabigatran) and factor $\mathrm{Xa}$ (apixaban, rivaroxaban, edoxaban). This new class of anticoagulants has a rapid onset (1-4 hours) and offset of action (about 24 hours). However, drug elimination is prolonged in patients with reduced renal clearance. Dabigatran is mostly eliminated by the kidneys $(\sim 80 \%),{ }^{37}$ edoxaban has $50 \%$ of the dose undergoing renal elimination, ${ }^{38}$ whereas rivaroxaban $(-33 \%)^{39}$ and apixaban $(-25 \%)^{40}$ are less affected by renal impairment. However, the use of DOACs should be cautious in patients with severe renal insufficiency (ie,

\begin{tabular}{|c|c|c|}
\hline \multirow{2}{*}{$\begin{array}{l}\text { Creatinine } \\
\text { clearance } \\
\text { (mL/min) }\end{array}$} & \multicolumn{2}{|c|}{$\begin{array}{l}\text { Timing of discontinuing DOACs before high-risk endoscopic } \\
\text { procedures (days) }\end{array}$} \\
\hline & Dabigatran & Apixaban/rivaroxaban/edoxaban \\
\hline$>80$ & 2 & 2 \\
\hline $50-80$ & 3 & 2 \\
\hline $30-50$ & 4 & 2 \\
\hline $15-30$ & Contraindicated & 2 \\
\hline$<15$ & Contraindicated & Not recommended \\
\hline
\end{tabular}

creatinine clearance $(\mathrm{CrCl}) 15-29 \mathrm{~mL} / \mathrm{min})$. No DOAC should be used in patients with $\mathrm{CrCl}<15 \mathrm{~mL} / \mathrm{min}$ (table 3). ${ }^{41-43}$

Hepatic impairment also increases the risk of bleeding. ChildPugh B cirrhosis affects the pharmacokinetics of rivaroxaban and apixaban (but not dabigatran) to a clinically relevant degree. Rivaroxaban is contraindicated in patients with Child-Pugh $\mathrm{B}$ and $\mathrm{C}$ cirrhosis. Apixaban should be used with caution in patients with Child-Pugh A or B cirrhosis. Dabigatran and apixaban are contraindicated in patients with advanced liver disease associated with coagulopathy, whereas in Japan edoxaban can be used with caution in patients with severe hepatic impairment. ${ }^{44}$

Unlike vitamin $\mathrm{K}$ antagonists, DOACs have a lower potential for drug-drug interactions. However, concomitant drugs that share the elimination pathways may increase the risk of bleeding. Apixaban and rivaroxaban are metabolised mainly via cytochrome P450 (CYP) 3A4-dependent and P-glycoprotein (P-gp)-dependent pathways. Strong inhibitors of both CYP3A4 and P-gp, such as ketoconazole and HIV protease inhibitors (eg, ritonavir), should not be co-administered with apixaban and rivaroxaban. ${ }^{39}$ Other concomitant drugs that may increase the risk of bleeding include antiplatelet agents and non-steroidal anti-inflammatory drugs (NSAIDs).

Neither the $\mathrm{ASGE}^{1}$ nor the $\mathrm{ESGE}^{2}$ Guidelines provide specific recommendations on acute bleeding with DOACs. Contrary to the BSG-ESGE Guidelines, ${ }^{3}$ we do not recommend the use of platelet transfusion or desmopressin in severe acute bleeding with DOACs because there is no clinical or laboratory evidence to support such practice. As mentioned in the section on acute bleeding with antiplatelet therapy, new data suggest that platelet transfusion is associated with increased mortality. ${ }^{7}$ Since prothrombin time (PT) and activated partial thromboplastin time (APTT) do not necessarily indicate whether anticoagulation is supratherapeutic, therapeutic or subtherapeutic in patients receiving DOACs, the BSG-ESGE Guidelines ${ }^{3}$ recommend using specific assays to measure the anticoagulant activity of DOACs in acute bleeding. However, we do not make this recommendation because assessment of the anticoagulant activity of DOACs requires specific assays that are not routinely available. Furthermore, withholding DOACs will lead to rapid loss of anticoagulation due to their short half-lives unless the patient has impaired renal clearance.

Management of acute bleeding in patients receiving DOACs depends on the severity of bleeding, timing of the last dose of DOAC, creatinine clearance and the pharmacokinetic properties of individual DOACs. Since DOACs are not vitamin K antagonists, vitamin $\mathrm{K}$ is not useful as an antidote to overdose of DOACs. For bleeding that is not life-threatening, standard haemodynamic support measures and temporary cessation of DOACs is probably sufficient due to their short half-lives. For severe bleeding with haemodynamic instability, we recommend the use of activated charcoal if the last dose of DOAC is taken within less than 3 hours. Our panel recommends a time window of 3 hours because most DOACs reach their peak plasma concentration within 3 hours of oral ingestion, although one healthy volunteer study suggested that activated charcoal can substantially reduce the terminal half-life of apixaban 6 hours postdose. ${ }^{45}$ However, the efficacy of activated charcoal has not been evaluated in clinical practice. On the other hand, we do not recommend dialysis as a treatment option, with the exception of dabigatran, because the other three DOACs have high protein binding and therefore are not dialyzable. ${ }^{46}$

Both the ASGE Guidelines ${ }^{1}$ and the BSG-ESGE Guidelines ${ }^{3}$ are cautious about the use of FFP and PCC in life-threatening bleeding with DOACs. We reviewed the literature and found 
that there is no human study on FFP for the reversal of the anticoagulant effect of DOACs. In fact, FFP is unlikely to be effective because it will be required to overcome the direct inhibitory effect of DOACs rather than replenishing depleted factors as in the case of reversal of warfarin. One randomised trial of healthy volunteers showed that a non-activated 4-factor PCC reversed the prolonged PT with rivaroxaban but did not normalise the APTT or thrombin time with dabigatran. ${ }^{47}$ To date, there have not been any human studies on the efficacy of PCC either on laboratory bleeding time or clinical bleeding associated with DOACs. In October 2015 the Food and Drug Administration in the USA granted accelerated approval to idarucizumab, a potent monoclonal antibody directed against dabigatran, for use in patients during emergency situations. In a multicentre open-label study of 503 patients who had uncontrolled bleeding or were about to undergo an urgent procedure, $5 \mathrm{~g}$ of idarucizumab reversed the anticoagulant effect of dabigatran within 4 hours in almost all patients. ${ }^{48}$ While current evidence demonstrates the capacity of idarucizumab to reverse laboratory abnormalities of dabigatran-associated coagulopathy, its clinical benefit is still unclear because of the scarcity of available data.

Specific recommendations on the timing of re-initiation of DOACs after endoscopic haemostasis for acute bleeding are not available in the ASGE, ESGE or BSG-ESGE Guidelines. ${ }^{1-3}$ After haemostasis has been achieved, we recommend early resumption of DOACs without bridging therapy with heparin. Our recommendation is based on the fact that DOACs have short terminal half-lives (about 12 hours) in patients without impaired renal clearance. It follows that the residual antiacoagulant effect will be minimal after the first 3 days and early resumption of DOACs is needed for patients with high thrombotic risk. Bridging therapy is not necessary since these drugs have a rapid onset of action (between 1 and 4 hours). We do not consider re-initiation of DOACs should be deferred because of concerns about early rebleeding in the absence of specific antidotes. Our local experience suggests that management of rebleeding after resumption of DOACs in a controlled environment is predictable compared with patients with severe bleeding due to toxic ingestion of DOACs.

\section{Triple and double antithrombotic therapies}

In patients with both non-valvular atrial fibrillation and acute coronary syndrome or coronary stenting, a short period of triple antithrombotic therapy (ie, DAPT and an oral anticoagulant) followed by double therapy (ie, single antiplatelet agent and an oral anticoagulant) for up to 1 year is often required. The optimal management of antithrombotic therapy after bleeding remains uncertain because large-scale clinical outcome data are not available. The European Society of Cardiology (ESC) Working Group on Thrombosis ${ }^{49}$ recommends stopping either aspirin or clopidogrel in patients who develop bleeding during triple therapy. In addition, they recommend discontinuation of antiplatelet agent when a patient develops bleeding on double therapy. In patients with non-valvular atrial fibrillation and low risk of stroke who develop bleeding during triple or double therapy, however, they recommend DAPT alone without oral anticoagulant for 1 year after acute coronary syndrome or coronary stenting. Given the complexity of these cases, our Task Force believes that communication with a cardiologist to make individualised decisions is essential.
SUMMARY OF RECOMMENDATIONS: ELECTIVE ENDOSCOPY

\section{A. Low-risk procedures}

Single antiplatelet agent

21. We do not recommend withholding antiplatelet agents. (A+ 71\%, A 21\%, D 7\%; strong recommendation; moderate-quality evidence)

Dual antiplatelet therapy

22. We do not recommend stopping both antiplatelet agents. (A+ 64\%, A 29\%, D 7\%; weak recommendation; low-quality evidence)

\section{Warfarin}

23. We do not recommend withholding warfarin. (A+75\%, A $17 \%$, D- 8\%; strong recommendation; low-quality evidence)

a. Keep the INR within the therapeutic range before the procedure.

b. For patients on warfarin, defer the endoscopic procedure if the INR exceeds 3.5 before the endoscopy.

\section{DOACs}

24. We do not suggest omitting DOACs. (A+ 25\%, A 59\%, A$8 \%$, D $8 \%$; weak recommendation; low-quality evidence)

\section{B. High-risk/ultra-high risk procedures}

Single antiplatelet agent

25. We do not recommend discontinuation of aspirin except in ultra-high risk procedures. (A+60\%, A 30\%, A- 10\%; strong recommendation; low-quality evidence)

26. We recommend withholding P2Y12 receptor inhibitor 5 days before the procedure. (A+33\%, A 67\%; strong recommendation; moderate-quality evidence)

27. We recommend resuming P2Y12 receptor inhibitor once adequate haemostasis has been achieved. (A+ 43\%, A 43\%, A- 14\%; strong recommendation; low-quality evidence)

\section{Dual antiplatelet therapy (DAPT)}

28. Except for ultra-high risk procedures that may require stopping both antiplatelet agents, we recommend withholding P2Y12 receptor inhibitor for 5 days before the procedure while aspirin should be continued. (A+ 43\%, A 50\%, D $7 \%$; strong recommendation; low-quality evidence)

29. We recommend resuming P2Y12 receptor inhibitor once adequate haemostasis has been achieved. (A+ 43\%, A 43\%, A- $14 \%$; strong recommendation; low-quality evidence)

\section{Warfarin}

30. We recommend stopping warfarin 5 days before the procedure. (A+33\%, A 67\%; weak recommendation; low-quality evidence)

31. In patients with low thromboembolic risk, we recommend endoscopic procedures to be undertaken if INR is below 2.0. (A+ 82\%, A 9\%, A- 9\%; strong recommendation; low-quality evidence)

32. In patients with high thromboembolic risk, we recommend bridging with heparin when INR is below 2.0 before endoscopic procedures. (A+ 55\%, A 45\%; strong recommendation; low-quality evidence)

33. We recommend resuming warfarin once adequate haemostasis has been achieved. (A+ 55\%, A 45\%; strong recommendation; low-quality evidence) 
34. In patients with high thromboembolic risk, we recommend bridging with heparin after the procedure until INR reaches therapeutic range. $(\mathrm{A}+55 \%$, A 27\%, A- 18\%; strong recommendation; low-quality evidence)

\section{DOACs}

35. We recommend withholding DOACs at least 48 hours before the procedure. $(\mathrm{A}+30 \%$, A 70\%; strong recommendation; low-quality evidence)

36. We do not recommend bridging anticoagulation. (A+55\%, A 45\%; strong recommendation; low-quality evidence)

37. We recommend resuming DOACs after adequate haemostasis has been achieved. (A+ 45\%, A 55\%; strong recommendation; low-quality evidence)

\section{Low-risk procedures}

Both the ASGE $^{1}$ and ESGE-BSG Guidelines ${ }^{3}$ have stratified endoscopic procedures into low risk and high risk for bleeding. The stratification was largely based on retrospective observational studies where the majority of the patients undergoing endoscopy did not receive antithrombotics. Furthermore, there is no international consensus on the definition a high-risk procedure. For example, enteral stenting is classified as low risk in the ASGE Guidelines $^{1}$ and high risk in the ESGE-BSG Guidelines. ${ }^{3}$

Our Task Force classifies those procedures with bleeding risk less than $1 \%$ as low risk. Low-risk procedures include diagnostic procedures with mucosal biopsies and therapeutic procedures without cutting open the mucosa or breaching the deep layers (table 1). We do not recommend interruption of antiplatelet agents or anticoagulants for patients undergoing these procedures. Mucosal biopsy while continuing antithrombotics is thought to be safe. Apart from a retrospective observational study, ${ }^{50}$ one randomised trial of aspirin versus clopidogrel in healthy volunteers found no bleeding events in the aspirin group and one minor endoscopic bleeding event in the clopidogrel group. ${ }^{51}$ Only one retrospective study, which was conducted in Japan, reported the safety of performing biopsy in patients on more than one antithrombotic drug. Among 112 patients, where 30 patients were on multiple antithrombotic agents, no patients experienced bleeding symptoms in the 2 -week observation period after biopsy. However, the bleeding time was up to 9 min in four patients who had multiple biopsies. ${ }^{52}$ There are no studies on the safety of biopsies in patients receiving the newer antiplatelet drugs (prasugrel, ticagrelor, vorapaxar) or DOACs. The risk of bleeding with double balloon enteroscopy in patients not on antithrombotic drugs has been reported at $0.2 \%,{ }^{53}$ but there are no studies on enteroscopy in patients receiving antiplatelet drugs or anticoagulants.

\section{Ultra-high risk procedures}

Both ASGE $^{1}$ and BSG-ESGE ${ }^{3}$ Guidelines are comparable in their classification of high-risk procedures. In general, there is consensus between professional societies that aspirin can be safely continued in patients undergoing procedures with a high bleeding risk. The BSG-ESGE Guidelines ${ }^{3}$ recommend continuing aspirin in all high-risk procedures with the exception of ESD, large colonic endoscopic mucosal resection (EMR) $(>2 \mathrm{~cm})$, upper gastrointestinal EMR and ampullectomy. Our Task Force has further stratified high-risk procedures into highrisk and ultra-high risk. The latter includes ESD and EMR of large $(>2 \mathrm{~cm})$ polyps. Unlike the BSG-ESGE Guidelines, ${ }^{3}$ we do not classify ampullectomy as an ultra-high risk procedure as our regional data suggest that aspirin can be continued for patients with high thrombotic risk. ${ }^{54}$ We recommend interruption of all antithrombotic agents for ultra-high risk procedures provided that the perceived benefits of the procedure outweigh the patient's thrombotic risk. However, decisions have to be individualised after liaison with cardiologists or neurologists. We believe it is important to add this category of ultra-high procedures in the Asian Pacific region because: (1) these procedures (eg, ESD) are frequently performed in this part of the world; (2) many studies in the literature were conducted in Asia; and (3) the conflicting outcomes reflect different standards of care and levels of expertise.

Two observational studies have assessed the risk of delayed post-polypectomy bleeding after EMR of polyps $>2 \mathrm{~cm}$ while continuing antithrombotic drugs, but the results are conflicting. Burgess et al studied 101 patients (68 patients continuing aspirin, 14 patients on warfarin interrupted without bridging therapy, and 19 patients on warfarin interrupted with bridging therapy) and the use of antithrombotics was not associated with delayed post-polypectomy bleeding. ${ }^{55}$ In contrast, Mertz et al reported that aspirin use was an independent risk factor for delayed bleeding with large colonic EMR after multivariate analysis. The incidence of bleeding with aspirin was reported at $29.4 \%$ (5/17 patients). ${ }^{56}$ Duodenal EMR carries a high risk of bleeding, reportedly at $12.3 \%(14 / 113)^{57}$ and $6.3 \%(7 / 11)^{58}$ from two observational studies. There are no studies reporting the incidence of bleeding after duodenal EMR in patients receiving antithrombotics.

ESD carries a higher risk of bleeding than EMR, irrespective of location of lesion in the GI tract (OR 2.20 95\% CI 1.58 to 3.07). ${ }^{59}$ The rate of bleeding with gastric ESD ranges from $3.6 \%$ to $6.9 \% .^{60-62}$ The risk of bleeding with continuation of aspirin in gastric ESD has yielded conflicting results. These retrospective observational studies reported either no increased risk ${ }^{63-66}$ or increased risk of bleeding. ${ }^{6768}$ However, most of these studies do not have a control group of non-aspirin users and do not differentiate between antiplatelet drugs and anticoagulants. No studies have reported the rate of bleeding with ESD in patients receiving non-aspirin antiplatelet drugs.

\section{High-risk procedures}

\section{Colonoscopy and polypectomy}

Observational data on patients receiving aspirin and undergoing polypectomy suggest that continuation of aspirin as monotherapy does not increase the risk of bleeding. ${ }^{69-71} \mathrm{~A}$ meta-analysis of five observational studies (two published in abstract form only) of 574 subjects continuing clopidogrel and 6179 controls reported an increased risk of delayed post-polypectomy bleeding with continued clopidogrel therapy (pooled relative risk 4.66, $96 \%$ CI 2.37 to 9.17$).^{72}$ There are no data on the incidence of post-polypectomy bleeding in patients receiving new antiplatelet drugs.

Current guidelines on the management of anticoagulation for polypectomy are largely based on expert opinion. Two retrospective observational studies reported the incidence of delayed bleeding with uninterrupted warfarin at $0 \%(0 / 21)^{73}$ and $0.8 \%$ $(1 / 123) .{ }^{74}$ All the patients had prophylactic clipping after polypectomy. One prospective study compared cold snaring versus hot snaring of small colonic polyps $(<1 \mathrm{~cm})$ in patients with uninterrupted warfarin. The rate of delayed bleeding was $0 \%$ with cold snaring and 14\% (5/35) with hot snaring. ${ }^{75}$ There are no direct reports on the bleeding risk in patients treated with DOACs undergoing colonoscopy. According to the safety data of the RE-LY trial, which compared dabigatran and warfarin for 
prevention of thromboembolism in 4591 patients, about 10\% of the patients underwent colonoscopy. There was no significant difference in peri-procedural bleeding risk between the two groups. ${ }^{76}$

\section{Endoscopic retrograde cholangiopancreatography (ERCP) and sphincterotomy}

Only a few studies have reported the risk of bleeding with continuation of antiplatelet drugs in patients undergoing ERCP and sphincterotomy. Using a nationwide database in Japan, Hamada et al reported that both sphincterotomy and balloon dilatation can be performed safely in patients taking aspirin. ${ }^{77}$ A small observational study reported 95 patients with uninterrupted antithrombotic therapy undergoing ERCP with minimal sphincterotomy and balloon dilation (aspirin plus clopidogrel in 55 patients, aspirin plus an anticoagulant in 45 patients, and triple therapy with aspirin plus clopidogrel plus an anticoagulant in five patients). Among them, 14 received DOACs. The overall bleeding rate was $4 \%{ }^{78}$

Endoscopic ultrasound (EUS) with fine needle aspiration (FNA) The risk of bleeding from EUS-FNA is around 1\%.9 ${ }^{80}$ For EUS-FNA of pancreas cystic lesions, the rate of bleeding is up to $6 \%{ }^{81}$ In a prospective observational study, the bleeding rates with EUS-FNA were $0 \%(0 / 26), 33.3 \%(2 / 6)$ and $3.7 \%(7 / 90)$ in patients receiving aspirin/NSAIDs, LMWH and no drugs. ${ }^{82}$ There are no studies investigating the safety of EUS-FNA with continuation of non-aspirin antiplatelet drugs, warfarin or DOACs.

\section{Percutaneous endoscopic gastrostomy (PEG)}

In a retrospective analysis of 990 patients undergoing PEG, the rates of bleeding were $3.6 \%$ and $2.7 \%$ with aspirin and clopidogrel, respectively. ${ }^{83}$ In another retrospective study of 450 patients, no post-PEG bleeding was observed in patients using anticoagulants including heparin and vitamin $\mathrm{K}$ antagonists. ${ }^{84}$ No studies exists on the safety of PEG in users of DOACs.

To date there is no convincing evidence that prophylactic endoscopic treatment can reduce the risk of bleeding in patients receiving antithrombotics. Pooled analyses from two separate meta-analyses have reported that prophylactic measures reduce the risk of post-polypectomy bleeding. ${ }^{858}$ However, it is uncertain whether the benefit can be extrapolated to patients receiving antithrombotics as all studies excluded patients receiving antiplatelet drugs or anticoagulants.

\section{Risk of cardiac events following endoscopy in patients with coronary stents}

There are no direct data on the risk of major adverse cardiac events (MACEs) following GI endoscopy in patients with coronary stents. According to the 2014 American College of Cardiology (ACC)/American Heart Association (AHA) Guidelines, ${ }^{87}$ the risk of ACEs in patients undergoing non-cardiac surgery is high in those with drug-eluting coronary stents (DES) placed within 12 months or bare metal coronary stents (BMS) placed within 1 month. The American College of Chest Physicians recommends that surgery should be deferred for at least 6 weeks after placement of a BMS and for at least 6 months after placement of a DES ${ }^{88}$ However, recent evidence derived from a US national retrospective cohort study of about 42000 Veterans Affairs (VA) and non-VA operations in the 24 months after a coronary stent placement found that the risk of MACEs is actually comparable between DES and BMS. The risk is highest within the first 6 weeks, remains high from 6 weeks to 6 months and then becomes stable after 6 months. Importantly, DES is not a significant risk factor for MACEs. Three important risk factors for MACEs are emergency surgery, a history of myocardial infarction within 6 months prior to surgery, and a revised cardiac index greater than $2 .^{89}$ The latter is available as an online preoperative surgical risk calculator that includes a history of myocardial infarction, a history of cerebrovascular accident, a history of congestive heart failure, diabetes mellitus requiring preoperative insulin and renal impairment (creatinine $>176.8$ $\mu \mathrm{mol} / \mathrm{L}$ or $2 \mathrm{mg} / \mathrm{dL}$ ). ${ }^{90}{ }^{91}$ The European Society of Cardiology (ESC) Working Group on Thrombosis classified the risk of thrombosis into five categories according to the timing of acute coronary syndrome and percutaneous coronary intervention, type of coronary stents and presence of other cardiac risk factors. ${ }^{49}$ Our Task Force has simplified the thrombotic risk into three categories (very high, high, moderate to low) to guide the management of antithrombotic therapy for elective endoscopic procedures with high bleeding risk (table 2).

\section{Thrombotic risk with interruption of antithrombotics When to stop and resume antiplatelet drugs?}

If endoscopic procedures with high bleeding risks are deemed necessary, we recommend withholding P2Y12 receptor inhibitor for 5-7 days before the procedure while aspirin should be continued. In a large US registry, the median time to stent thrombosis can be as short as 7 days when both antiplatelet drugs are withheld whereas the median time is prolonged to 122 days when one antiplatelet drug is continued. ${ }^{11}$ Among patients without coronary stents the risk of myocardial infarction or stroke depends on the indication of antiplatelet therapy. The thrombotic risk without antiplatelet therapy is 10 -fold higher in secondary prevention than in primary prevention $(3.11 \%$ vs $0.34 \%$ yearly). ${ }^{92}$

Given the high bleeding risks associated with ultra-high risk procedures, our Task Force recommends withholding all antiplatelet agents provided that the perceived benefits of the procedure outweigh the patient's thrombotic risk. The total duration of interruption should not exceed 7 days due to a high risk of coronary stent thrombosis. Decisions have to be individualised after liaison with cardiologists or neurologists.

We recommend discontinuing a P2Y12 receptor inhibitorwith the exception of ticagrelor which has a shorter duration of action-5 days before high-risk procedures while continuing aspirin based on the following expert opinion: (1) the effect of non-aspirin antiplatelet drugs will last for up to 5 days (about 3 days for ticagrelor) after taking the last dose; and (2) P2Y12 receptor inhibitor is more potent than aspirin, thereby carrying a high bleeding risk. In contrast, the ASGE guidelines recommend withholding P2Y12 receptor inhibitors for at least 5-7 days before high-risk procedures. ${ }^{1}$ We are concerned about the thrombotic risk of prolonged discontinuation of these antiplatelet drugs, especially in patients with DES.

There are no data on the optimal timing of resuming antiplatelet drugs after elective endoscopic procedures. In patients who are at risk of coronary stent thrombosis, our Task Force recommends resumption of P2Y12 receptor inhibitor once adequate haemostasis has been achieved.

\section{Interruption of anticoagulants}

The BSG-ESGE Guidelines ${ }^{3}$ stratify the risk of thromboembolism into two groups (low risk and high risk) whereas the ASGE Guidelines $^{1}$ stratify patients into three groups according to the 
estimated annual risk of thromboembolism without anticoagulation (low risk $(<5 \%)$, medium risk $(5-10 \%)$ and high risk $(>10 \%))$. Our Task Force has made recommendations on the use of heparin bridging with interruption of warfarin (box 2).

\section{Atrial fibrillation}

For patients who have non-valvular atrial fibrillation, the risk of thromboembolism can be estimated using the $\mathrm{CHA}_{2} \mathrm{DS}_{2}-\mathrm{VASc}$ score. ${ }^{9394}$ The total score ranges from 0 to 9 : congestive cardiac failure (1 point), hypertension ( 1 point), age $\geq 75$ ( 2 points), diabetes (1 point), stroke ( 2 points), vascular disease (prior myocardial infarction, peripheral artery disease, aortic plaque; 1 point), age $65-75$ years (1 point), female sex (1 point). Patients with a score of $\geq 2$ are prescribed anticoagulants (estimated annual risk of thromboembolism $>2.2 \%$ ). In the BSG-ESGE Guidelines, ${ }^{3}$ low-risk patients include all patients with non-valvular atrial fibrillation but their $\mathrm{CHA}_{2} \mathrm{DS}_{2}$-VASc scores are not considered. Only those with atrial fibrillation associated with mitral stenosis or prosthetic heart valves are considered as high risk.

\section{Mechanical heart valves}

The risk of thromboembolism in patients with mechanical heart valves depends on the type, number and position of the valve and the presence of underlying heart failure or atrial fibrillation. ${ }^{95}$ Our Task Force recommends heparin bridging for patients with a metallic mitral valve alone or a metallic valve with atrial fibrillation (box 2).

\section{Venous thromboembolism (VTE)}

The risk thromboembolism after VTE depends on the timing of VTE. Our Task Force recommends heparin bridging in patients with VTE within 3 months (box 2). However, no studies have assessed the risk of thromboembolism in high-risk patients without bridging therapy.

\section{Thrombophilia syndromes}

Some patients are predisposed to venous thrombosis. There is a wide spectrum of thrombophilia syndromes ranging from isolated laboratory abnormalities with a low thrombotic risk (eg, Factor V Leiden and the prothrombin mutation F2G20210A) to high-risk conditions such as antiphospholipid syndromes, deficiencies of antithrombin, protein $\mathrm{C}$ or protein $\mathrm{S}$ (box 2).

\section{When to stop and resume warfarin?}

There is very little evidence to guide when to stop warfarin prior to endoscopy. Recommendations are largely based on expert opinion. Our Task Force recommends stopping warfarin 5 days before endoscopy. We recommend resuming warfarin once adequate haemostasis has been achieved.

\section{Bridging therapy}

Bridging therapy is provided to those patients at high risk of thromboembolism (box 2). To date, only one large-scale randomised trial of patients with atrial fibrillation on warfarin undergoing an elective invasive procedure found that no heparin bridging was not inferior to bridging for prevention of thromboembolism. There was a significantly higher risk of bleeding in the bridging group compared with the no bridging group $(1.3 \%$ vs $3.2 \%, \mathrm{P}=0.005)$. However, the findings cannot be extrapolated to patients with a high thromboembolic risk as only a small proportion of patients had mitral stenosis or CHA2DS2VASc score $>5 .^{96}$ Based on the above evidence, our Task Force recommends heparin bridging for non-valvular atrial fibrillation if the $\mathrm{CHA}_{2} \mathrm{DS}_{2}$-VASc score is $>5$. In contrast, the ASGE Guidelines recommend heparin bridging if the $\mathrm{CHA}_{2} \mathrm{DS}_{2}$-VASc score is $>2{ }^{1}$

The choice of heparin formulations and the optimal timing of bridging therapy remain uncertain. A large prospective non-randomised study showed there was no difference in adverse events with bridging therapy using unfractionated heparin or LMWH in patients with mechanical heart valves. ${ }^{97}$ Observational studies on surgical patients showed no difference in risk of bleeding between the last dose of LMWH being given at 12 hours compared with that of 24 hours before surgery. ${ }^{98} 99$ Given the fact that heparin bridging is associated with a significantly higher risk of bleeding than no bridging, our Task Force recommends heparin bridging when INR falls $<2$ before high-risk procedures.

There are no direct studies investigating the timing for re-starting heparin after endoscopy. A few observational studies support re-initiation of warfarin within 24 hours. $^{9798100}$ It is commonly agreed among professional societies that heparin should be resumed once haemostasis is secured.

There is no evidence to support the use of bridging therapy in patients receiving DOACs. Bridging therapy is indicated in patients with very high thrombotic risk such as mechanical heart valves but DOACs are not indicated for such patients. Furthermore, interruption of DOACs during the peri-endoscopic period is brief because DOACs have a short half-life and rapid onset of action.

\section{When to stop and resume DOACS?}

No studies are available to guide the optimal time for discontinuation or resumption of DOACs for endoscopic procedures. Currently available guidelines are conflicting. The ASGE Guidelines recommend continuation of DOACs for low-risk procedures and discontinuing anticoagulation according to the pharmacokinetic properties of individual DOACs for high-risk procedures. ${ }^{1}$ The BSG-ESGE Guidelines suggest omitting the morning dose of DOACs on the day of low-risk procedures and recommend the last dose of DOACs be taken at least 48 hours before high-risk procedures. ${ }^{3}$ Given the minimal bleeding risk associated with diagnostic endoscopy and mucosal biopsy, our Task Force does not suggest omitting DOACs before low-risk procedures. For high-risk procedures, our recommendation depends on the choice of DOAC (dabigatran vs other DOACs) and the patient's creatinine clearance (table 3 ). For patients on dabigatran, the last dose should be taken 48 hours before the procedure if the renal function is normal $(\mathrm{CrCl}>80 \mathrm{~mL} / \mathrm{min})$. Lengthening the period of discontinuation is required in patients with renal impairment because $80 \%$ of dabigatran metabolite is excreted by the kidneys (table 3 ). For patients on other DOACs (apixaban, rivaroxaban and edoxaban), we recommend the last dose should be taken 48 hours before the procedure provided that $\mathrm{CrCl}$ is $>15 \mathrm{~mL} / \mathrm{min} .{ }^{101}$ Since DOACs have short half-lives and rapid onset of action, heparin bridging is not recommended. We recommend early resumption of DOACs after haemostasis has been achieved.

\section{Author affiliations}

'Department of Medicine and Therapeutics, The Chinese University of Hong Kong, Hong Kong, China

${ }^{2}$ Department of Gastroenterology and Hepatology, University of Malaya, Kuala Lumpur, Malaysia

${ }^{3}$ Asian Healthcare Foundation, AAll India Institute of Medical Sciences, Hyderabad, Andhra Pradesh, India

${ }^{4}$ Department of Internal Medicine and Gastrointestinal Endoscopy, Saga Medical College, Saga, Japan 
${ }^{5}$ Division of Gastroenterology and Hepatology, Department of Medicine, National University Singapore, Singapore, Singapore

${ }^{6}$ Department of Cardiovascular Medicine, Graduate School of Medical Sciences, Kumamoto University, Kumamoto, Japan

${ }^{7}$ Department of Internal Medicine, Gyeongsang National University School of Medicine and Cardiovascular Center, Gyeongsang, Republic of Korea

${ }^{8}$ Department of Clinical Medicine, Kyushu University, Fukuoka, Japan

${ }^{9}$ Department of Gastroenterology, Korea University College of Medicine, Seoul, Republic of Korea

${ }^{10}$ Department of Medicine, Chulalongkorn University, Bangkok, Thailand

${ }^{11}$ Jockey Club School of Public Health and Primary Care, The Chinese University of Hong Kong, Hong Kong, China

${ }^{12}$ Department of Internal Medicine, National Taiwan University Hospital, Taipei, Taiwan

${ }^{13}$ Department of Medicine and Therapeutics, Institute of Vascular Research, The Chinese University of Hong Kong, Hong Kong, China

${ }^{14}$ Department of Medicine, Division of Gastroenterology, Jichi Medical School, Tochigi, Japan

Acknowledgements We are most indebted to Dr Neena Abraham for her expert opinion in preparing the initial set of our practice guidelines.

Contributors FKLC, SH and KS produced the first draft of the practice guideline statements. KKFT did the literature search and systematic review. All authors actively participated in the modified Delphi process to revise the statements. FKLC wrote the initial draft of the manuscript. All authors have read, revised and approved the final manuscript.

Funding Funding of this joint task force was derived from an educational grant from the Institute of Digestive Disease of CUHK and sponsorship from Takeda Pharmaceuticals Company Limited.

Competing interests FKLC has served as a consultant to Eisai, Pfizer, Takeda and Otsuka. He has been paid lecture fees by Eisai, Pfizer, AstraZeneca and Takeda. KLG has served as a consultant to Takeda and has received lecture fees from Reckitt Beckinser, AstraZeneca, Eisai and Takeda. SH has received lecture fees from Takeda, AstraZeneca, Eisai, Pfizer, Bristol Myers Squibb, MSD, Sanofi and Daiichi Sankyo. Y-HJ has received honoraria for lectures from AstraZeneca, Sanofi-Aventis, Daiichi Sankyo/Lilly, Haemonetics, Otsuka, Han-mi Pharmaceuticals and Yuhan Pharmaceuticals; and research grants or support from AstraZeneca, Korean Society of Interventional Cardiology, Han-mi Pharmaceuticals, Yuhan Pharmaceuticals, Otsuka and Haemonetics. TK has received speaker fees from Bayer Yakuhin and Daiichi Sankyo, consulting fees from Chugai Pharmaceutical and grant support from Takeda Pharmaceutical, Daiichi Sankyo, Mitsubishi Tanabe Pharma, Eisai, Astellas Pharma, Chugai Pharmaceutical and MSD. KYH has received lecture fees from Olympus. BPY has served as a consultant to AstraZeneca, Pfizer and Daiichi Sankyo. He has received research grants or support from AstraZeneca, Pfizer, Daiichi Sankyo, Boehringer Ingelheim and Bayer. KS has received lecture fees from Takeda AstraZeneca, Eisai, Astellas and Fujjifim. DNR, KF, HSL, VM, KKFT and MSW have nothing to declare.

\section{Provenance and peer review Not commissioned; externally peer reviewed.}

Open Access This is an Open Access article distributed in accordance with the Creative Commons Attribution Non Commercial (CC BY-NC 4.0) license, which permits others to distribute, remix, adapt, build upon this work non-commercially, and license their derivative works on different terms, provided the original work is properly cited and the use is non-commercial. See: http://creativecommons.org/ licenses/by-nc/4.0/

(c) Article author(s) (or their employer(s) unless otherwise stated in the text of the article) 2018. All rights reserved. No commercial use is permitted unless otherwise expressly granted.

\section{REFERENCES}

1 Acosta RD, Abraham NS, Chandrasekhara V, et al. The management of antithrombotic agents for patients undergoing GI endoscopy. Gastrointest EndosC 2016:83:3-16

2 Gralnek IM, Dumonceau JM, Kuipers EJ, et al. Diagnosis and management of nonvariceal upper gastrointestinal hemorrhage: European Society of Gastrointestinal Endoscopy (ESGE) Guideline. Endoscopy 2015;47:a1-46.

3 Veitch AM, Vanbiervliet G, Gershlick AH, et al. Endoscopy in patients on antiplatelet or anticoagulant therapy, including direct oral anticoagulants: British Society of Gastroenterology (BSG) and European Society of Gastrointestinal Endoscopy (ESGE) guidelines. Gut 2016:65:374-89.

4 The GRADE Working Group. 2016.www.gradeworkinggroup.org(accessed 30 Jul 2016)

5 Ikeda Y, Shimada K, Teramoto T, et al. Low-dose aspirin for primary prevention of cardiovascular events in Japanese patients 60 years or older with atherosclerotic risk factors: a randomized clinical trial. JAMA 2014;312:2510-20.
6 Saito Y, Okada S, Ogawa $\mathrm{H}$, et al. Low-dose aspirin for primary prevention of cardiovascular events in patients with type 2 diabetes mellitus: 10-year follow-up of a randomized controlled trial. Circulation 2017;135:659-70.

7 Zakko L, Rustagi T, Douglas M, et al. No benefit from platelet transfusion for gastrointestinal bleeding in patients taking antiplatelet agents. Clin Gastroenterol Hepatol 2017:15:46-52

8 Sung JJ, Lau JY, Ching JY, et al. Continuation of low-dose aspirin therapy in peptic ulcer bleeding: a randomized trial. Ann Intern Med 2010;152:1-9.

9 Derogar M, Sandblom G, Lundell L, et al. Discontinuation of low-dose aspirin therapy after peptic ulcer bleeding increases risk of death and acute cardiovascular events. Clin Gastroenterol Hepatol 2013;11:38-42.

10 Kukreja N, Onuma Y, Garcia-Garcia HM, et al. The risk of stent thrombosis in patients with acute coronary syndromes treated with bare-metal and drug-eluting stents. JACC Cardiovasc Interv 2009;2:534-41.

11 Eisenberg MJ, Richard PR, Libersan D, et al. Safety of short-term discontinuation of antiplatelet therapy in patients with drug-eluting stents Circulation 2009: 119: 1634-42.

12 Yamada S, Onda M, Kato S, et al. Genetic differences in CYP2C19 single nucleotide polymorphisms among four Asian populations. J Gastroenterol 2001;36:669-72.

13 Lee VW, Chau TS, Chan AK, et al. Pharmacogenetics of esomeprazole or rabeprazolebased triple therapy in Helicobacter pylori eradication in Hong Kong non-ulcer dyspepsia Chinese subjects. J Clin Pharm Ther 2010;35:343-50.

14 Chan FK. Anti-platelet therapy and managing ulcer risk. J Gastroenterol Hepatol 2012;27:195-9.

15 U.S. Food and Drug. FDA reminder to avoid concomitant use of Plavix (clopidogrel) and omeprazole. https://www.fda.gov/Drugs/DrugSafety/ucm231161.htm

16 Simon T, Steg PG, Gilard M, et al. Clinical events as a function of proton pump inhibitor use, clopidogrel use, and cytochrome P450 2C19 genotype in a large nationwide cohort of acute myocardial infarction: results from the French Registry of Acute ST-Elevation and Non-ST-Elevation Myocardial Infarction (FAST-MI) registry. Circulation 2011;123:474-82.

17 Wallentin L, Becker RC, Budaj A, et al. Ticagrelor versus clopidogrel in patients with acute coronary syndromes. N Engl J Med 2009;361:1045-57.

18 Wiviott SD, Braunwald E, McCabe CH, et al. Prasugrel versus clopidogrel in patients with acute coronary syndromes. N Engl J Med 2007:357:2001-15.

19 Morrow DA, Braunwald E, Bonaca MP, et al. Vorapaxar in the secondary prevention of atherothrombotic events. N Eng/ J Med 2012;366:1404-13.

20 Tran HA, Chunilal SD, Harper PL, et al. An update of consensus guidelines for warfarin reversal. Med J Aust 2013;198:198-9.

21 Patriquin C, Crowther M. Treatment of warfarin-associated coagulopathy with vitamin K. Expert Rev Hematol 2011:4:657-67.

22 Choudari CP, Rajgopal C, Palmer KR. Acute gastrointestinal haemorrhage in anticoagulated patients: diagnoses and response to endoscopic treatment. Gut 1994:35:464-6.

23 Wolf AT, Wasan SK, Saltzman JR. Impact of anticoagulation on rebleeding following endoscopic therapy for nonvariceal upper gastrointestinal hemorrhage. Am J Gastroenterol 2007;102:290-6

24 Shingina A, Barkun AN, Razzaghi A, et al. Systematic review: the presenting international normalised ratio (INR) as a predictor of outcome in patients with upper nonvariceal gastrointestinal bleeding. Aliment Pharmacol Ther 2011:33:1010-8.

25 Karaca MA, Erbil B, Ozmen MM. Use and effectiveness of prothrombin complex concentrates vs fresh frozen plasma in gastrointestinal hemorrhage due to warfarin usage in the ED. Am J Emerg Med 2014;32:660-4.

26 Dentali F, Marchesi C, Giorgi Pierfranceschi M, et al. Safety of prothrombin complex concentrates for rapid anticoagulation reversal of vitamin $\mathrm{K}$ antagonists. A metaanalysis. Thromb Haemost 2011;106:429-38.

27 Hickey M, Gatien M, Taljaard M, et al. Outcomes of urgent warfarin reversal with frozen plasma versus prothrombin complex concentrate in the emergency department. Circulation 2013;128:360-4.

28 Holbrook A, Schulman S, Witt DM, et al. Evidence-based management of anticoagulant therapy: Antithrombotic Therapy and Prevention of Thrombosis, 9th ed: American College of Chest Physicians Evidence-Based Clinical Practice Guidelines. Chest 2012:141:e152S-84

29 Patel RJ, Witt DM, Saseen JJ, et al. Randomized, placebo-controlled trial of oral phytonadione for excessive anticoagulation. Pharmacotherapy 2000;20:1159-66.

30 Crowther MA, Julian J, McCarty D, et al. Treatment of warfarin-associated coagulopathy with oral vitamin $\mathrm{K}$ : a randomised controlled trial. Lancet 2000:356:1551-3.

31 Crowther MA, Douketis JD, Schnurr T, et al. Oral vitamin K lowers the international normalized ratio more rapidly than subcutaneous vitamin $\mathrm{K}$ in the treatment of warfarin-associated coagulopathy. A randomized, controlled trial. Ann Intern Med 2002:137:251-4

32 Lubetsky A, Yonath $\mathrm{H}$, Olchovsky D, et al. Comparison of oral versus intravenous phytonadione (vitamin $\mathrm{K} 1$ ) in patients with excessive anticoagulation: a prospective randomized controlled study. Arch Intern Med 2003:163:2469-73.

33 Witt DM, Delate T, Garcia DA, et al. Risk of thromboembolism, recurrent hemorrhage and death after warfarin therapy interruption for gastrointestinal tract bleeding. Arch Intern Med 2012;172:1484-91. 
34 Lee JK, Kang HW, Kim SG, et al. Risks related with withholding and resuming anticoagulation in patients with non-variceal upper gastrointestinal bleeding while on warfarin therapy. Int J Clin Pract 2012;66:64-8.

35 Qureshi W, Mittal C, Patsias I, et al. Restarting anticoagulation and outcomes after major gastrointestinal bleeding in atrial fibrillation. Am J Cardiol 2014;113:662-8.

36 Eikelboom JW, Hankey GJ. Low molecular weight heparins and heparinoids. Med Aust 2002;177:379-83.

37 Trocóniz IF, Tillmann C, Liesenfeld KH, et al. Population pharmacokinetic analysis of the new oral thrombin inhibitor dabigatran etexilate (BIBR 1048) in patients undergoing primary elective total hip replacement surgery. J Clin Pharmacol 2007:47:371-82

38 Heidbuchel $H$, Verhamme P, Alings M, et al. European Heart Rhythm Association practical guide on the use of new oral anticoagulants in patients with non-valvular atrial fibrillation. EP Europace 2013;15:625-51.

39 Mueck W, Kubitza D, Becka M. Co-administration of rivaroxaban with drugs that share its elimination pathways: pharmacokinetic effects in healthy subjects. Br J Clin Pharmacol 2013;76:455-66.

40 Zhang D, He K, Raghavan N, et al. Comparative metabolism of 14C-labeled apixaban in mice, rats, rabbits, dogs, and humans. Drug Metab Dispos 2009;37:1738-48.

41 Weitz JI, Quinlan DJ, Eikelboom JW. Periprocedural management and approach to bleeding in patients taking dabigatran. Circulation 2012;126:2428-32.

42 Dzik WS. Reversal of drug-induced anticoagulation: old solutions and new problems. Transfusion 2012;52(Suppl 1):45S-55.

43 Heidbuchel $H$, Verhamme $P$, Alings $M$, et al. European heart rhythm association practical guide on the use of new oral anticoagulants in patients with non-valvular atrial fibrillation. Europace 2013:15:625-51.

44 Graff J, Harder S. Anticoagulant therapy with the oral direct factor Xa inhibitors rivaroxaban, apixaban and edoxaban and the thrombin inhibitor dabigatran etexilate in patients with hepatic impairment. Clin Pharmacokinet 2013;52:243-54

45 Wang X, Mondal S, Wang J, et al. Effect of activated charcoal on apixaban pharmacokinetics in healthy subjects. Am J Cardiovasc Drugs 2014;14:147-54.

46 Khadzhynov D, Wagner F, Formella $\mathrm{S}$, et al. Effective elimination of dabigatran by haemodialysis. A phase I single-centre study in patients with end-stage renal disease. Thromb Haemost 2013;109:596-605.

47 Eerenberg ES, Kamphuisen PW, Sijpkens MK, et al. Reversal of rivaroxaban and dabigatran by prothrombin complex concentrate: a randomized, placebo-controlled, crossover study in healthy subjects. Circulation 2011;124:1573-9.

48 Pollack CV, Reilly PA, van Ryn J, et al. Idarucizumab for dabigatran reversal - full cohort analysis. N Engl J Med 2017;377:431-41.

49 Halvoren S, Storey RF, Rocca B, et al. Management of antithrombotic therapy after bleeding in patients with coronary artery disease and/or atrial fibrillation: expert consensus paper of the European Society of Cardiology Working Group on Thrombosis. Euro Heart J 2017:38:1455-62.

50 Gerson LB, Gage BF, Owens DK, et al. Effect and outcomes of the ASGE guidelines on the periendoscopic management of patients who take anticoagulants. Am J Gastroenterol 2000;95:1717-24.

51 Whitson MJ, Dikman AE, von Althann C, et al. Is gastroduodenal biopsy safe in patients receiving aspirin and clopidogrel? A prospective, randomized study involving 630 biopsies. J Clin Gastroenterol 2011:45:228-33.

52 Ono S, Fujishiro M, Kodashima S, et al. Evaluation of safety of endoscopic biopsy without cessation of antithrombotic agents in Japan. J Gastroenterol 2012:47:770-4.

53 Gerson LB, Tokar J, Chiorean M, et al. Complications associated with double balloon enteroscopy at nine US centers. Clin Gastroenterol Hepatol 2009;7:1177-82.

54 Bassan M, Bourke M. Endoscopic ampullectomy: a practical guide. J Interv Gastroenterol 2012:2:23-30.

55 Burgess NG, Metz AJ, Williams SJ, et al. Risk factors for intraprocedural and clinically significant delayed bleeding after wide-field endoscopic mucosal resection of large colonic lesions. Clin Gastroenterol Hepatol 2014;12:651-61.

56 Metz AJ, Bourke MJ, Moss A, et al. Factors that predict bleeding following endoscopic mucosal resection of large colonic lesions. Endoscopy 2011;43:506-11.

57 Nonaka S, Oda I, Tada K, et al. Clinical outcome of endoscopic resection for nonampullary duodenal tumors. Endoscopy 2015;47:53-7.

58 Qumseya BJ, Wolfsen C, Wang Y, et al. Factors associated with increased bleeding post-endoscopic mucosal resection. J Dig Dis 2013;14:140-6.

59 Cao Y, Liao C, Tan A, et al. Meta-analysis of endoscopic submucosal dissection versus endoscopic mucosal resection for tumors of the gastrointestinal tract. Endoscopy 2009;41:751-7.

60 Miyahara K, Iwakiri R, Shimoda R, et al. Perforation and postoperative bleeding of endoscopic submucosal dissection in gastric tumors: analysis of 1190 lesions in lowand high-volume centers in Saga, Japan. Digestion 2012;86:273-80.

61 Toyokawa T, Inaba T, Omote S, et al. Risk factors for perforation and delayed bleeding associated with endoscopic submucosal dissection for early gastric neoplasms: analysis of 1123 lesions. J Gastroenterol Hepatol 2012:27:907-12.

62 Toyonaga T, Man-i M, East JE, et al. 1,635 Endoscopic submucosal dissection cases in the esophagus, stomach, and colorectum: complication rates and long-term outcomes. Surg Endosc 2013;27:1000-8.
$63 \mathrm{Lim} \mathrm{JH}, \mathrm{Kim} \mathrm{SG}, \mathrm{Kim}$ JW, et al. Do antiplatelets increase the risk of bleeding after endoscopic submucosal dissection of gastric neoplasms? Gastrointest Endosc 2012;75:719-27

64 Tounou S, Morita Y, Hosono T. Continuous aspirin use does not increase postendoscopic dissection bleeding risk for gastric neoplasms in patients on antiplatelet therapy. Endosc Int Open 2015;3:E31-8.

65 Tsuji Y, Ohata K, Ito T, et al. Risk factors for bleeding after endoscopic submucosal dissection for gastric lesions. World J Gastroenterol 2010;16:2913-7.

66 Jeon SW, Jung MK, Cho CM, et al. Predictors of immediate bleeding during endoscopic submucosal dissection in gastric lesions. Surg Endosc 2009;23:1974-9.

67 Cho SJ, Choi IJ, Kim CG, et al. Aspirin use and bleeding risk after endoscopic submucosal dissection in patients with gastric neoplasms. Endoscopy 2012;44:114-21.

68 Sanomura Y, Oka S, Tanaka S, et al. Continued use of low-dose aspirin does not increase the risk of bleeding during or after endoscopic submucosal dissection for early gastric cancer. Gastric Cancer 2014;17:489-96

69 Hui AJ, Wong RM, Ching JY, et al. Risk of colonoscopic polypectomy bleeding with anticoagulants and antiplatelet agents: analysis of 1657 cases. Gastrointest Endosc 2004;59:44-8.

70 Shiffman ML, Farrel MT, Yee YS. Risk of bleeding after endoscopic biopsy or polypectomy in patients taking aspirin or other NSAIDS. Gastrointest Endosc 1994:40:458-62.

71 Yousfi M, Gostout CJ, Baron TH, et al. Postpolypectomy lower gastrointestinal bleeding: potential role of aspirin. Am J Gastroenterol 2004;99:1785-9.

72 Gandhi S, Narula N, Mosleh W, et al. Meta-analysis: colonoscopic post-polypectomy bleeding in patients on continued clopidogrel therapy. Aliment Pharmacol Ther 2013;37:947-52

73 Friedland S, Soetikno R. Colonoscopy with polypectomy in anticoagulated patients. Gastrointest Endosc 2006;64:98-100.

74 Friedland S, Leung CW, Soetikno RM. Colonoscopy with polypectomy in patients taking clopidogrel. Gastroenterology Res 2009;2:209-12.

75 Horiuchi A, Nakayama Y, Kajiyama M, et al. Removal of small colorectal polyps in anticoagulated patients: a prospective randomized comparison of cold snare and conventional polypectomy. Gastrointest Endosc 2014;79:417-23.

76 Healey JS, Eikelboom J, Douketis J, et al. Periprocedural bleeding and thromboembolic events with dabigatran compared with warfarin: results from the Randomized Evaluation of Long-Term Anticoagulation Therapy (RE-LY) randomized trial. Circulation 2012;126:343-8.

77 Hamada T, Yasunaga H, Nakai Y, et al. Bleeding after endoscopic sphincterotomy or papillary balloon dilation among users of antithrombotic agents. Endoscopy 2015; 47:997-1004

78 Mok SR, Arif M, Diehl DL, et al. Safety and efficacy of minimal biliary sphincterotomy with papillary balloon dilation (m-EBS+EPBD) in patients using clopidogrel or anticoagulation. Endosc Int Open 2017:5:E157-E164.

79 Al-Haddad M, Wallace MB, Woodward TA, et al. The safety of fine-needle aspiration guided by endoscopic ultrasound: a prospective study. Endoscopy 2008;40:204-8.

80 Mortensen MB, Fristrup C, Holm FS, et al. Prospective evaluation of patient tolerability, satisfaction with patient information, and complications in endoscopic ultrasonography. Endoscopy 2005;37:146-53.

81 Varadarajulu S, Eloubeidi MA. Frequency and significance of acute intracystic hemorrhage during EUS-FNA of cystic lesions of the pancreas. Gastrointest Endosc 2004:60:631-5

82 Kien-Fong Vu C, Chang F, Doig L, et al. A prospective control study of the safety and cellular yield of EUS-guided FNA or Trucut biopsy in patients taking aspirin, nonsteroidal anti-inflammatory drugs, or prophylactic low molecular weight heparin. Gastrointest Endosc 2006;63:808-13

83 Richter JA, Patrie JT, Richter RP, et al. Bleeding after percutaneous endoscopic gastrostomy is linked to serotonin reuptake inhibitors, not aspirin or clopidogrel. Gastrointest Endosc 2011:74:22-34.

84 Ruthmann 0, Seitz A, Richter S, et al. [Percutaneous endoscopic gastrostomy. Complications with and without anticoagulation]. Chirurg 2010;81:247-54.

85 Corte CJ, Burger DC, Horgan G, et al. Postpolypectomy haemorrhage following removal of large polyps using mechanical haemostasis or epinephrine: a metaanalysis. United European Gastroenterol J 2014:2:123-30.

86 Ly L, Liu QS, Li L, et al. A meta-analysis and systematic review of prophylactic endoscopic treatments for postpolypectomy bleeding. Int J Colorectal Dis 2011;26:709-19.

87 Fleisher LA, Fleischmann KE, Auerbach AD, et al. ACC/AHA guideline on perioperative cardiovascular evaluation and management of patients undergoing noncardiac surgery: a report of the American College of Cardiology/American Heart Association Task Force on practice guidelines. J Am Coll Cardiol 2014:64:e77-137.

88 Douketis JD, Spyropoulos AC, Spencer FA, et al. Perioperative management of antithrombotic therapy: Antithrombotic Therapy and Prevention of Thrombosis, 9th ed: American College of Chest Physicians Evidence-Based Clinical Practice Guidelines. Chest 2012;141:e326S-50.

89 Hawn MT, Graham LA, Richman JS, et al. Risk of major adverse cardiac events following noncardiac surgery in patients with coronary stents. JAMA 2013;310:1462-72. 
90 Holcomb CN, Graham LA, Richman JS, et al. The incremental risk of noncardiac surgery on adverse cardiac events following coronary stenting. J Am Coll Cardiol 2014;64:2730-9.

91 MD-CALC. Revised cardiac risk index for pre-operative risk. https://www.mdcalc. com/revised-cardiac-risk-index-pre-operative-risk

92 Baigent $\mathrm{C}$, Blackwell L, Collins R, et al. Aspirin in the primary and secondary prevention of vascular disease: collaborative meta-analysis of individual participant data from randomised trials. Lancet 2009:373:1849-60.

93 Pearce LA, Hart RG, Halperin JL. Assessment of three schemes for stratifying stroke risk in patients with nonvalvular atrial fibrillation. Am J Med 2000;109:45-51.

94 Gage BF, van Walraven C, Pearce L, et al. Selecting patients with atrial fibrillation for anticoagulation: stroke risk stratification in patients taking aspirin. Circulation 2004; 110:2287-92.

95 Cannegieter SC, Rosendaal FR, Briet E. Thromboembolic and bleeding complications in patients with mechanical heart valve prostheses. Circulation 1994;89:635-41.

96 Douketis JD, Healey JS, Brueckmann M, et al. Perioperative bridging anticoagulation during dabigatran or warfarin interruption among patients who had an elective surgery or procedure. Substudy of the RE-LY trial. Thromb Haemost 2015;113:625-32.

97 Spyropoulos AC, Turpie AG, Dunn AS, et al. Perioperative bridging therapy with unfractionated heparin or low-molecular-weight heparin in patients with mechanical prosthetic heart valves on long-term oral anticoagulants (from the REGIMEN Registry). Am J Cardiol 2008;102:883-9.

98 Douketis JD, Johnson JA, Turpie AG. Low-molecular-weight heparin as bridging anticoagulation during interruption of warfarin: assessment of a standardized periprocedural anticoagulation regimen. Arch Intern Med 2004;164:1319-26.

99 Kovacs MJ, Kearon C, Rodger M, et al. Single-arm study of bridging therapy with low-molecular-weight heparin for patients at risk of arterial embolism who require temporary interruption of warfarin. Circulation 2004;110:1658-63.

100 Dunn A. Perioperative management of oral anticoagulation: when and how to bridge. J Thromb Thrombolysis 2006;21:85-9.

101 Heidbuchel H, Verhamme P, Alings M, et al. Updated European Heart Rhythm Association practical guide on the use of non-vitamin-K antagonist anticoagulants in patients with non-valvular atrial fibrillation: Executive summary. Eur Heart 2017;38:2137-49. 